University of South Florida

DIGITAL COMMONS

Digital Commons @ University of

@ UNIVERSITY OF SOUTH FLORIDA

South Florida

Academic Services Faculty and Staff

Publications

Tampa Library

2013

\title{
Planned Flexibility for Course Reserves
}

LeEtta M. Schmidt

University of South Florida, Imschmidt@usf.edu

Follow this and additional works at: https://digitalcommons.usf.edu/tlas_pub

Part of the Library and Information Science Commons

\section{Scholar Commons Citation}

Schmidt, LeEtta M., "Planned Flexibility for Course Reserves" (2013). Academic Services Faculty and Staff Publications. 178.

https://digitalcommons.usf.edu/tlas_pub/178

This Article is brought to you for free and open access by the Tampa Library at Digital Commons @ University of South Florida. It has been accepted for inclusion in Academic Services Faculty and Staff Publications by an authorized administrator of Digital Commons @ University of South Florida. For more information, please contact digitalcommons@usf.edu. 


\section{Planned Flexibility for Course Reserves}

It is hard to deny, that we are living in times of exceptionally rapid change. Systems that reinvented and revitalized education and librarianship only a few years ago have grown outmoded and unsupported. Student and patron needs have simply grown. And seemingly everyone, everywhere, is looking to squeeze everything they can imagine from the systems and processes they have, or they are looking elsewhere. This should come as no surprise: though; innovation can be a constant, the really big changes always seem to come in waves. If we tried to pin down what is driving the wave we are riding, we might find that our expectations have changed. We no longer look at a system or process and think, 'Wow! I never imagined anything could do all of that!' Now, we look at a new system and demand, 'but, why doesn't it do this too?'

More than a decade ago, course reserves faced the revolution of electronic content delivery. Many libraries cobbled together solutions using systems at hand to provide protected access to online course material (Brinkman, Lavallee-Welch \& Paul, 2004; Dick \& Ferguson, 2006; Bombeld \& Pfohl, 2004). The intricacies of these homemade systems and the unique needs of electronic reserves created an environment where the multiple functions of reserves became more and more separate in their processes and accessibility. Fast forwarding to the present revolution in course reserves sees a growing need to centralize service points, data recording, and assessment measures (Dick \& Ferguson, 2006; Peters \& Sanney, 2012; Hansen, Cross \& Edwards, 2013).

Shopping for new solutions, however, is not easy when integration is the name of the game. The rise in course management systems for holding and delivering content to both distance and in-person students has made it necessary for libraries to connect course materials to 
course management (Clumpner, Burgmeier, \& Gillespie, 2011; Peters \& Sanney, 2012; Holobar, 2006). Holobar warns that a parallel and separate development of online course management from library-provided online course content "places academic libraries at a risk of becoming peripheral” (2006, p. 66). Reserves can no longer exist as an island of its own. While this may seem like just another requirement on the shopping list for the new course reserves solution, it represents a much larger issue. If a course reserves system must be integrated into other systems and programs, then, in addition to the ability to connect, a course reserves solution must also be changeable in response to the changes in other systems.

At the University of South Florida, around the end of 2011, what began as the need to reevaluate our course reserves delivery system was brewing into the proverbial "perfect storm.” It started with the university's decision to move from one problem-ticketing software to another. RightNow ticketing software was in widespread use on campus for information technology reporting, billing, and accounting services, as well as for patron services in the library. Request or problem reporting forms were be imbedded in library web pages. The reserves request form asked for all the class and item information, alerted reserves staff that a new ticket was created and tracked the ticket history. It offered the ability to add multiple items to one form, which, though useful for faculty, made tracking difficult when any one item in a ticket required different action or took longer to resolve. Additionally, multiple areas of reserves all had different forms that asked for different information. Though cumbersome, these processes would probably have remained in place, even with the faults of offering reserves services through ticketing software, until RightNow was being eliminated, since the proposed replacement incurred additional cost per each user account. This meant that using it for most library services (where many staff 
members managed tickets) would become unacceptably expensive. There needed to be another way.

At the same time, another part of the storm front was moving in. USF was looking for solutions to the problems of exorbitant textbook costs, student financial need, and legislative demands for greater access to higher education. The library at USF began investigating the possibilities of using reserves as the textbook delivery point in partnership with the university bookstore and publishers, similar to the program at Urbana-Champaign described by Laskowski (2007). This special program would be integrated into the reserves collection, yet separate in process and handling. Within the current system, however, it would add to the duplicative, cumbersome, and isolated processes already in place. There needed to be another way.

Technology grant to the rescue! Technology fees, charged to students with tuition, fund a pot of money that students, staff and faculty can apply to use on projects that will enhance technology resources for learning on campus (Information Technology, 2013). Our application proposed a new textbook support initiative as part of a complete overhaul of the existing course reserves service. This new service would need a system that could integrate all existing reserves request and fulfillment processes, and it would include new equipment to process e-reserves requests, staffing to handle the improved services, and an annual license to cover the copyright needs of e-reserves faculty patrons. A new high output, wide bed scanner, Ares course reserves system, dedicated part time staff, and the CCC Academic annual license would fill these needs

\section{New Opportunities}

Similar to that of the University of Maryland and others, USF's electronic reserves system had evolved piecemeal over time, relying on outdated paper forms and cumbersome work processes. Existing communication methods produced few faculty responses to emails 
requesting updates on reserve materials (Dick \& Ferguson, 2006). By moving all existing processes to Ares, the service points for physical reserves, electronic reserves, media reserves, and the new textbooks on reserve would all be combined. Referral of any given request from one process to another would become seamless. The new system would also allow more standardized communication with acquisitions for items that may need to be ordered. It would also connect with the course management system in a way that placed the request and delivery points for the service directly in faculty courses. Planning for the service launch began with multi-departmental meetings and ended with new understanding of departmental needs on all sides. Far different from an island, reserves was seen as a puzzle piece in an all-encompassing service (Clumpner, Burgmeier, \& Gillespie, 2011).

The acquisition of textbooks continued with the help of the university bookstore and were cataloged and shelved alongside all other reserves. Even in the new reserves system, the processes were still exclusive since the items acquired through the textbook project were not based on faculty requests at all. Filtering all titles through one system, however, revealed that textbooks acquired through the bookstore were also fulfilling some faculty requests. Like the University of Illinois at Urbana-Champaign, USF had not initially involved faculty and so needed to reach out and advertise textbook program and enhanced reserves services (Laskowski, 2007). It was hoped that by incorporating a little extra marketing into the normal reserves communications about request fulfillment, the textbook program could gain faculty support and involvement so important to the health of library services (Poe, 2006).

The pre-existing processes of reserves had made it nearly impossible to get comprehensive statistics and request data. Requests made through the ticketing system often included more than one item and offered no way to track changes on the ticket without opening 
each one. As had been reported by so many other libraries, the lack of reliable and centralized tracking had made copyright reporting and service management difficult and inexact (Hansen, Cross \& Edwards, 2013). The new system made each item or title an individual request, eliminating the problem of the RightNow system that generated one ticket request with multiple statuses. It also tracked copyright and faculty use of the system from semester to semester.

\section{The Plan in Our Hip Pocket}

The Ares committee, created to guide the implementation of the new system and composed of representatives from multiple library services, wanted some customizations before launching a new and improved service. Partly inspired by other library service systems’ success with a transition to a single sign-on environment, and partly in deference to a previous seamless authentication initiative in USF's Information Technology department, the USF library asked for dual sign-on methods. Although Ares would be connected with the course management system, Blackboard, to ensure that reserves services were where they needed to be, the library also wanted the ability to direct users through a web log-in. In the nebulous and hazy future, there

might be a course or program that needed course reserves service but did not exist in Blackboard. This was the prediction, and the explanation offered for the dual sign-on method request. In order for course reserves patrons to access the same patron record through both log-in methods, the web log-in pages would be enabled by Shibboleth and patron authentication would pull from the same data source that defined them in Blackboard. Having this option, though unneeded at the time, added flexibility to the system for challenges unforeseen.

\section{Moving to the New System}


The improved service launch, or, more accurately, service migration, took place over three phases. The first phase, moving e-reserves delivery to Ares, occurred over the fall 2011 semester. Electronic reserves had previously been supplied to faculty through the course content mechanism in Blackboard. Teaching and helping the faculty find their material in a new place was be the easiest part of patron re-education, and might help when it was time to move the request location. Faculty would still make their e-reserves request through the old RightNow web forms, but the PDFs would be delivered to the newly embedded Ares pages within the faculty member's course page in Blackboard.

The second phase, over the spring 2012 semester, entailed managing requests from dual systems. Library staff created web pages and tutorials, instructing faculty how to place requests from within Blackboard, and instructing students how to find lists of reserves and e-reserves materials in Blackboard. An announcement of the new and improved service was included in a library services outreach email from the reference librarians. During this time staff still received requests in RightNow, as well as in person, over the phone, and via email, in addition to working with requests in Ares. After the start of semester rush, staff began entering all requests received from all methods into Ares. This provided intensive practice for the staff, and ensured there were no requests dropped between systems. It also provided a way to make the transition easier for faculty by saying 'here are all your materials, and this is also where you can request more, and renew your requests for next semester.' At the end of the semester, outreach emails told faculty of the move and connected them with tutorials and information pages.

The third and final phase, over the summer 2012 semester, was turning off reserves processing in RightNow. The web pages were re-written a final time and all access to the old RightNow forms was removed. Henceforth, all physical, electronic, and media reserves would 
be handled through the same system, with similar processing steps and unified labeling. All staff emails included reminders about how to use the new system and where to get information. By the fall 2012 semester the new service and staff processes were firmly in place. Another outreach email at the end of the fall 2012 semester encouraged the early placement of reserves requests for spring 2013 and asked for feedback on the service improvements. It was hoped that the survey would involve faculty and enhance their opinion of the library (Poe, 2006; Peters \& Sanney, 2012), as well as mitigate the frustration of faculty who had managed to avoid learning the new system.

Library services are pinned to the calendar of patron demands they meet. The natural cycle of reserves makes it difficult to change a service at the most convenient time for both staff and faculty (Bombeld \& Pfohl, 2004). USF's three-phase plan accepted that staff would be faced with an increased workload due to double entry, and attempted to place this phase in a less demanding semester while reserving the easiest semester, summer, for the full transition.

\section{Statistical Review and Survey Data}

E reserves request records from spring semesters 2011 and 2012 were checked for counts of unique material titles, courses, faculty users, and method of upload. Faculty use of e-reserves was expected to increase with the implementation of the new reserves system.

Spring of 2012 showed a 145.6\% increase from 2011 in material titles for 20\% more unique faculty users

- $87 \%$ of all electronic reserves in spring 2012 were loaded by faculty requestors

- However, less than $1 \%$ of USF faculty and instructors used electronic reserves in spring 2012 
Figure 1.1 shows E-reserves request numbers from spring 2010 to mid-fall 2012

(October). Faculty reliance on library services for e-reserves showed a decline until the use of Ares for e-reserves in fall 2011. Most of the early Ares adoptees during spring 2012 loaded their own content. Starting in summer 2012 and continuing into fall 2012, the percentage of faculty requests filled by staff increased.

$<$ figure 1.1>

Identifying any changes in the use of physical reserves before and after the service migration presented difficulties. Like Randall Library at the University of North Carolina, Wilmington, USF found that the systems in place before Ares did not track adequately enough to give a good picture of the launch (Bombeld \& Pfohl, 2004). Based on the observations of the staff, reserve item counts for fall 2011 and fall 2012 do not vary by much.

Only 8\% of faculty emailed at the end of spring 2012 responded to the survey. This is the typical response rate that reserves usually gets from its updates and outreach communications. Of the $8 \%$ who responded, nearly all had staff or librarian assistance when accessing the new system for the first time. Considering the number of e-reserves users who uploaded their own content during the launch, this $8 \%$ may reflect a group of faculty who interact with the library more often, thus are more likely to respond to the survey, and not representative of all reserves users. The faculty respondents also found it easy to place requests in the new system and were satisfied with the transition.

\section{What We Didn't Think of in Advance}

Although USF's service improvement included interdepartmental cooperation and the combining of many processes into a more seamless service, a few other related and unforeseen 
processes came under scrutiny during the transition. It became apparent that there were several similar course material support points in the library, all handled by different processes and personnel. The supply of physical textbooks on reserves was only one part of the whole Textbook Affordability Program. Other parts, like E-Books in the Classroom (an on-demand supply of electronic texts for in class use), addressed the same need, but were not connected either within the library or without, on library web pages. Similarly, the supply of links to streaming media for faculty in-class or distant education was completely separate in process, personnel, and service location. One way to mitigate patron confusion was to expand the reserves web pages to address or refer to the Textbook Affordability Program's scope and limitations and to the streaming digital media options for in-class teaching.

Ares also made it very easy for staff to forward faculty requests for books and media directly to acquisitions. The library had always attempted to purchase un-owned material for reserves, but had not developed any type of policy or uniform process for handling these requests. The new system resulted in a large influx of faculty requests for materials that the USF libraries do not own, and made it necessary to create criteria for reserves and acquisitions staff to determine whether the library can purchase a volume requested for reserves. These criteria include descriptions for when reserves may be able to fill the request through the USF Textbook Affordability program.

\section{Did We See This Coming?}

USF course reserves returned to the plan in our hip pocket. After our successful launch of course reserves with Ares, the reserves team was confronted with yet another system change decided by University Information Technology. Blackboard was scheduled to be replaced by 
Canvas, an Instructure product. All courses and faculty within Blackboard would be migrated to the new system within a year and a half.

Preliminary investigation showed that while Ares did not have any specific connection in place interface with Canvas, the same tables that allowed Moodle and Angel to work with Ares would also allow a Canvas connection via a Basic LTI (Learning Tool Interoperability) (Fagen \& Gregory, 2013). However, our first tests encountered problems that were eventually traced to the way Ares creates users who enter through Canvas. Like the University of Nevada discovered, established users in Ares were not connecting to the new system (Adams \& Fisher, 2012).

The problem involved the external ID that Ares recorded from each system. When a patron attempted to enter reserves through Canvas, Ares would try to match the ID sent by Canvas to an existing user record. If that record did not exist, Ares would create the user. However, usernames are unique in the Ares database. When an existing user, Jane Doe, with an external ID created by Blackboard attempted to enter reserves through Canvas, Ares would not find an external ID match and would try to create a new user with USF NetID jdoe. At this point, Ares would see that jdoe already existed in the database and, therefore, could not be duplicated. Every existing Ares user who attempted to connect via Canvas would get this error. New users would not.

The purpose of connecting Ares to Blackboard was to put course reserves in courses, where it could be most easily used by faculty and students. The migration to Canvas meant that courses would be in multiple places. Integrating course reserves service into any and all course management systems the faculty used became the ideal solution, but it was an unattainable one. Ares could only support a connection to one course management system at a time. USF would focus on a migration of service from Blackboard to Canvas. This meant that any faculty who 
began using Canvas in advance of the migration, and those who continued to use Blackboard after the migration would not have a link to Ares course reserves available to them within the course management system.

Shibboleth enabled web login to the rescue! USF's initial desire to have access to Ares through single sign-on meant that existing users could log-in via the web. With this tool in hand, the reserves team could respond to any faculty request with a resounding 'Of course we can do that for you!' Faculty who needed electronic reserves just needed a little help from the reserves team to set up their course in Ares. Then, they were given the link for login, instructions for adding their students as authorized users and for importing the Ares web pages into the course management system as an embedded frame. For physical reserves, the reserve team processes devolved to email requests and manual entry of information into the system by staff.

\section{Another Service Migration}

We encountered a few more challenges as we planned to migrate course reserves service with Ares from Blackboard to Canvas. After we confirmed that the problem with both course management systems accessing Ares at the same time was due to the miss-match of external IDs for pre-existing users, we determined that migration would involve re-writing all the existing external IDs to match the new system. This required a list of values that Canvas used as its external ID.

The values that Canvas passes, however, and that Ares identifies, as the external IDs are randomly generated character combinations created at time of click. We could not possibly generate such a list. For a while it seemed as though the whole project would have to go back to the drawing board. The Shibboleth-enabled pages meant that reserves service could continue with Ares, but the integral function of connecting to the course management system seemed 
harder and harder to reach. "While the need to integrate library resources into the Course Management Systems may be obvious, the means to accomplish this goal is less so (Holobar, 2008, p. 70).” There needed to be a better way.

Happily, once everyone on the project, reserves coordinator, host company and University IT, started looking at what the systems didn't do, they began asking, 'hey, why doesn't it do this too?,' Ares developers stepped in to make it work. The values that Ares identified as the external IDs for user and course were written into the system in a way that could not be easily overridden by the Ares Customization manager, or administrative client. Other values passed by LTIs in course management systems could be defined, but the external IDs could not. By making the user external ID something that could be defined in the Ares customization manager, the migration could continue as planned.

Having Ares in place before the University's move to Canvas provided an unexpected benefit. Unlike Blackboard, Canvas does not have a course content area, where staff not involved in a course can upload content for faculty and students. Streaming reserves, for example, requires the secure supply of a link to a single course. This was not something that the library could handle through web pages or the catalog, and would be lost when the University finished its migration from Blackboard to Canvas. Ares makes it possible to deliver this link within courses so that only authenticated faculty and students of the course can retrieve it. The partnership with streaming reserves can develop towards eliminating yet another service point for what faculty regard as reserve material.

Course reserves service at the USF library has evolved from a complex, rigid, and outdated system to become flexible, seamless, and responsive to user and staff needs. We will continue to juggle the changes that inevitably come our way with being available wherever 
faculty need us, but we can do it because of a little pre-planned adaptability. With the help of partnerships established during the project and a commitment to be on the lookout for any opportunity to make a new plan for the hip pocket, USF's next innovation wave for reserves should be easy to ride. 


\section{References}

Adams, C., \& Fisher, E. S., fisherin@gvsu.edu. (2012). Optimizing electronic reserves processes with ares.

Bombeld, M., \& Pfohl, D. M. (2004). Migrating to a new reserve system: Implementing Docutek's ERes system. Journal of Interlibrary Loan, Document Delivery \& Electronic Reserves, 15(1), 31-41.

Brinkman, C. S., Lavallée-Welch, C., \& Paul, M. T. (2004). From pilot to program: Developing an E-reserves service. Kentucky Libraries, 68(2), 9-13

Clumpner, K. E., Burgmeier, M., \& Gillespie, T. J. (2011). Embedded course reserves: Piecing the puzzle together. Computers in Libraries, 31(4), 10-14.

Dick, M. L., \& Ferguson, J. E. (2006). Building a better course reserve system. Journal of Interlibrary Loan, Document Delivery \& Electronic Reserves, 16(4), 39-56.

Fagen, S. \& Gregory, K. (2013) Ares Customization Tables. Retrieved from: https://prometheus.atlassys.com/display/Ares/Ares+Customization+Tables\#AresCustomizationTables-Integration 
Hansen, D. R. 1., dhansen@law.berkeley.edu, Cross, W. M. 2., wmcross@ncsu.edu, \& Edwards, P. M. 3., pmedwards@vcu.edu. (2013). Copyright policy and practice in electronic reserves among ARL libraries. College \& Research Libraries, 74(1), 69-84.

Holobar, J. C. (2006). Electronic reserves and course management software: A collaborative model for large institutions. Journal of Interlibrary Loan, Document Delivery \& Electronic Reserves, 16(4), 65-71.

Information Technology. (2013) Student Technology Fee. Retrieved from http://www.usf.edu/it/about-us/student-technology-fee.aspx

Laskowski, M. S. The textbook problem: Investigating one possible solution. Library Collections, Acquisitions and Technical Services, 31, 161-170.

Peters, T., peter1t@cmich.edu, \& Sanney, K. J. 1. (2012). Leveraging strengths and meeting demands: The construction of a modern and comprehensive electronic reserves service at central michigan university. Journal of Interlibrary Loan, Document Delivery \& Electronic Reserves, 22(1), 17-31.

Poe, J. (2006). Marketing electronic reserves at a university library: Start spreading the news. Journal of Interlibrary Loan, Document Delivery \& Electronic Reserves, 16(4), 93-102.

Woodman, B. (2007). Promoting course and electronic reserves to campus faculty. Journal of Interlibrary Loan, Document Delivery \& Electronic Reserves, 17(1), 183-211. 
